Relations industrielles

Industrial Relations

\title{
Le Code civil et les rapports de classes, par D. Brunelle, Québec, Les Presses de l’Université du Québec, 1975, 119 pages.
}

\section{Rodrigue Blouin}

Volume 31, numéro 1, 1976

URI : https://id.erudit.org/iderudit/028692ar

DOI : https://doi.org/10.7202/028692ar

Aller au sommaire du numéro

Éditeur(s)

Département des relations industrielles de l'Université Laval

ISSN

0034-379X (imprimé)

1703-8138 (numérique)

Découvrir la revue

Citer ce compte rendu

Blouin, R. (1976). Compte rendu de [Le Code civil et les rapports de classes, par D. Brunelle, Québec, Les Presses de l’Université du Québec, 1975, 119 pages.] Relations industrielles / Industrial Relations, 31(1), 157-157.

https://doi.org/10.7202/028692ar

Tous droits réservés (C) Département des relations industrielles de l'Université Laval, 1976
Ce document est protégé par la loi sur le droit d'auteur. L'utilisation des services d'Érudit (y compris la reproduction) est assujettie à sa politique d'utilisation que vous pouvez consulter en ligne.

https://apropos.erudit.org/fr/usagers/politique-dutilisation/ 
listes qui commentent et critiquent son travail. À lire les commentaires, il ne semble pas que l'expérience ait été très heureuse: M. Yves Dulude de l'IRAT avoue l'échec de la formule, même si le Dr. Claude Fortier, président de la Société royale du Canada et le juge Alan B. Gold - qui avoue presque ne pas avoir lu l'ouvrage s'en déclarent enchantés (dans leurs commentaires d'une dizaine de lignes). En fait, deux «spécialistes" sur cinq, seulement, nous offrent des commentaires le moindrement consistants. M. Raymond Laliberté, ex-président de la C.E.Q., dont la confiance en la formule du panel était plus que mince au départ, a honnêtement joué le jeu jusqu'au bout. Il se dit en total désaccord avec les orientations de base du document et regrette n'avoir pu en influencer la rédaction. (M. Fortier voyait, lui, dans le rapport Desgagné un reflet fidèle du «consensus établi par les membres du panel », comme quoi on trouve de tout dans un livre). Sa critique porte à la fois sur la démarche de l'analyse et sur ses présupposés idéologiques: «Par choix idéologique tout autant que par commodité analytique, je préfère un schéma d'analyse qui ne restreigne pas obligatoirement le syndicalisme à la seule conception orthodoxe du faux équilibre du rapport des forces, au sein d'un système de relations pratiquement immuable» (p. 182). C'est le seul commentaire qui ajoute quelque chose d' "utile» au texte de M. Desgagné. L'autre spécialiste était M. Jacques St-Pierre, vice-recteur à l'Université de Montréal, qui s'est attardé à des points précis du texte, à des affirmations à nuances, etc.

Au total, cet ouvrage décevra plus qu'il ne satisfera: c'est un document qu'on a voulu objectif au point, peut-être, de l'aseptiser. Il nous apparaît plus que nécessaire, à ce moment-ci, d'accroître la somme de connaissances empiriques sur le syndicalisme universitaire en général et au Québec en particulier, si on veut en comprendre l'évolution. L'ouvrage de MM. Desgagné et Miller a justement besoin d'une contrepartie empirique qui permette la confrontation de leurs thèses à la réalité.

\section{Gilles DUSSAULT}

Université Laval

Le Code civil et les rapports de classes, par D. Brunelle, Québec, Les Presses de l'Université du Québec, 1975, 119 pages.

«Le travail ne peut pas devenir un jeu» (L. Marx).
Dans son ouvrage fortement inspiré de la dialectique marxiste, l'auteur réussit presqu'à nous convaincre que le travail renvoie, dans notre système juridique, à un état de servitude. L'analyse tend essentiellement à démontrer que le droit de la propriété privée et le contrat de travail déterminent des rapports capitalistes de production-distribution-consommation et instituent consécutivement des rapports de classes. Ces rapports capitalistes entraînent l'obligation de travailler pour vivre et asservissent le travailleur face aux propriétaires des moyens de production.

L'auteur étudie successivement «La propriété privée et le louage d'ouvrage» et «Le pouvoir sur le travail». Cette étude est suivie d' "Une analyse sociologique de la loi canadienne de l'assurance-chômage" . Tous ces thèmes ne sont que l'occasion pour rappeler les critiques classiques à l'encontre du système juridique libéral (bourgeois/capitaliste). Le principal mérite de cet ouvrage est d'avoir démontré que notre système ne consacre pas le droit aux travailleurs à une quote-part du produit social, reconnaissance d'où découlerait logiquement celle de la valeur «travailtemps " consacrée comme fondement social de la valeur des marchandises et biens. Exception faite de ce mérite, cette étude n'apporte rien de nouveau à la démarche traditionnelle du matérislisme dialectique. Il s'agit par contre de la première étude valable où le Code civil du Québec a été l'occasion de l'application de cette dialectique.

À notre avis, l'ouvrage de monsieur Brunelle devrait être lu par tous les juristes qui s'intéressent aux rapports de travail. Les lecteurs éventuels doivent cependant être avisés que l'analyse est conduite de façon très abstraite.

\section{Rodrigue BLOUIN}

Université Laval

Études de droit du travail offertes à André Brun, Paris, Librairie sociale et économique, 1974, 622 pages.

Les intéressés au droit du travail, et plus particulièrement au droit comparé du travail, seront plus que comblés en consultant les Études de droit du travail offertes au professeur André Brun. On concevra facilement au nombre de collaborateurs qui ont contribué à ce recueil jusqu'à quel point le professeur Brun a su marquer de sa présence les milieux universitaire et professionnel. 